\title{
Capillary zone electrophoresis for the analysis of glycoforms of cellobiohydrolase
}

\author{
Ruchi Gupta ${ }^{\mathrm{a}, *}$, Sara J. Baldock ${ }^{\mathrm{b}, 1}$, Peter R. Fielden ${ }^{\mathrm{b}, 2}$, Bruce D. Grieve ${ }^{\mathrm{a}, 3}$ \\ a School of Electrical and Electronics Engineering, The University of Manchester, Sackville Street Building, Sackville Street, Manchester M13 9PL, UK \\ ${ }^{\mathrm{b}}$ School of Chemical Engineering and Analytical Science, Manchester Interdisciplinary Biocentre, The University of Manchester, Oxford Road, Manchester M13 9PL, UK
}

\section{A R T I C L E I N F O}

\section{Article history:}

Received 4 March 2011

Received in revised form 8 June 2011

Accepted 9 June 2011

Available online $\mathrm{xxx}$

\section{Keywords:}

Biofuel

Capillary coating

Cellobiohydrolase

Electrophoresis

Glycoforms

Mannose

\begin{abstract}
A B S T R A C T
Cellobiohydrolase (CBH) is an important enzyme for the conversion of lignocellulosic biomass to ethanol. This work separated the glycoforms of $\mathrm{CBH}$ possessing different numbers of neutral mannoses using capillary zone electrophoresis (CZE) in a $50 \mathrm{mM}$, pH 7.5 phosphate buffer. The method analysed CBH in an intact form using a polyacrylamide coated fused silica capillary without requiring additives or labelling of the enzyme. The migration time of the major peak was found to be $21.6 \pm 0.1 \mathrm{~min}(n=3)$ and the approach is suitable for testing of batch-to-batch consistency of $\mathrm{CBH}$. Ease-of-use, automation and speed are the other benefits due to which the use of CZE for analysing glycoforms of CBH was concluded to be ideal.
\end{abstract}

(c) 2011 Published by Elsevier B.V.

\section{Introduction}

The N-glycans attached to proteins such as cellobiohydrolases $(\mathrm{CBH})$ secreted by filamentous fungi (e.g. Trichoderma reesei) contain different number of mannose (Man) groups [1] attached to the core (composed of a Mannose GlcNAc $_{2}$ sequence) [2]. Such microheterogeneities affect the structure, activity and function of the proteins [3] and hence their assessment is of primary importance. The glycosylation-related microheterogeneities can be investigated by studying either the oligosaccharides released from proteins or the intact glycoproteins. As the analysis of glycans requires detachment of carbohydrate moieties from glycoproteins, the accuracy of the results is dependent on the robustness of the methods used to release the oligosaccharides. Even if the oligosaccharides are released successfully, their analysis via commonly used techniques (e.g. high performance liquid chromatography [4], ion exchange chromatography [5,6], gas chromatography [7] and capillary zone electrophoresis (CZE) [8,9]) necessitates their derivatization [10] or use of alkaline buffers or special chemistries $[11,12]$. This in turn adds to the complexity

\footnotetext{
* Corresponding author. Tel.: +44 161306 2815; fax: +44 1613064789.

E-mail addresses: ruchi.gupta@postgrad.manchester.ac.uk (R. Gupta), sara.baldock@manchester.ac.uk (S.J. Baldock), peter.fielden@manchester.ac.uk (P.R. Fielden), bruce.grieve@manchester.ac.uk (B.D. Grieve).

1 Tel.: +44 161306 8900; fax: +44 1613065201 .

2 Tel.: +44 161306 4889; fax: +44161306 5201.

3 Tel.: +44161306 2815; fax: +441613064789.
}

and time of analysis. Therefore, in general, investigation of intact proteins to determine variations introduced due to glycosylation is preferred.

Traditionally, SDS-PAGE and isoelectric focusing were employed for analysis of intact glycoproteins [2]. To increase the automation capabilities and analysis speed, capillary IEF (CIEF) has, for example, been used to investigate the glycoforms of cellobiohydrolases [13]. However, due to the limited availability of whole column imaging systems, it is often necessary to transport focused protein zones through the detection point with a consequent possibility of loss of resolution. As proteins have a tendency to precipitate at a $\mathrm{pH}$ near their $\mathrm{pI}$, precipitation of the focused proteins is a potential problem with cIEF. In addition, hyphenation of cIEF with other techniques such as mass spectrometry (MS) is challenging. Nuclear magnetic resonance (NMR) $[14,15]$ and MS $[16,17]$ are other essential tools for obtaining structural and linkage information pertaining to carbohydrates and hence the identification of glycoforms. For example, Hui et al. [18] have analysed proteolytic fragments of cellulases using electrospray MS coupled to liquid chromatography to identify glycosylation sites. A review of glycoproteins analysis via capillary electrophoresis coupled MS is provided by Amon et al. [19]. However, NMR requires a large amount of sample [2] and MS is seldom used as a stand-alone technique [20-22]. Furthermore, these techniques are equipment intensive and require specialised skills. Therefore, several studies have been reported on the use of CZE with optical detection methods for routine analysis of glycoforms due to its high resolution, sensitivity, reduced analysis time and ease-of-use [23-25]. 
Taverna et al. [26] propose that a strategy for CZE analysis of glycoconjugates is to try electrolytes at the $\mathrm{pH}$ extremes, to ensure that at least a single peak can be identified, followed by testing $\mathrm{pHs}$ closer to the isoelectric point of the glycoprotein to improve glycoform separation. However, the majority of reported CZE methods are different from sample to sample and are not universally applicable. While some studies have found that the use of borate buffers of high concentration $(100-200 \mathrm{mM})$ and at $\mathrm{pH}$ values greater than 8 improve the resolution of CZE separation of glycoforms by forming negatively charged polyol-borate complexes [12], the other studies did not observe any improvement of the CZE separation of glycoconjugates with borate buffers [24]. The role of dynamic (e.g. using additives such as diaminoalkanes) and static (covalently linked polyacrylamide) coatings on the separation of glycoforms has also not been established with certainty [27]. Although a majority of studies have used alkaline buffers for CZE separation of high mannose containing glycoproteins such as ovalbumin [28], Yeung et al. [29] utilized $50 \mathrm{mM}$, pH 4.5 buffer containing $\beta$-Alanine and acetic acid for investigating the glycosylated-related microheterogeneities of high mannose containing ribonuclease $B$ and recombinant bone morphogenetic protein-2. While the CZE separation of high mannose containing glycoforms at alkaline $\mathrm{pH}$ appears to be based on a difference in charge, their separation at acidic $\mathrm{pH}$ (where mannose groups are neutral) is likely to be based on a difference in size [29]. Therefore, it appears that the factors governing the separation of glycoconjugates remain unclear. Hence, it is essential to perform a systematic study of all possible variables governing CZE separations in general, to develop a method for analysis of glycoforms.

This paper presents the first use of CZE for investigating the glycosylation-related microheterogeneities present in $\mathrm{CBH}$ which is an important component of a multi-enzyme mixture required for the conversion of lignocellulosic biomass to ethanol [30], in an intact form. The expression of $\mathrm{CBH}$ in heterologous hosts such as plants to reduce its cost affect the enzyme's glycosylation and hence its activity to degrade cellulose [31]. In this work, the separation of the glycoforms of $\mathrm{CBH}$ was accomplished using $15 \mathrm{mM}, \mathrm{pH} 4.5$ and $50 \mathrm{mM}, \mathrm{pH} 7.5$ phosphate electrolytes in a fused silica and a polyacrylamide coated fused silica capillary respectively without buffer additives and enzyme labelling. As the buffering capacity of phosphate buffer at $\mathrm{pH} 7.5$ is greater than at $\mathrm{pH} 4.5$, the repeatability of the migration time of the glycoconjugates of $\mathrm{CBH}$ in the former was higher than the latter method.

\section{Experimental}

\subsection{Chemicals}

18.2 M $\Omega$ water (Elga Maxima, Ultra Pure, Vivendi Water Systems, High Wycombe, UK) was used to prepare all sample solutions and electrolytes used in this work. Phosphate electrolytes of various $\mathrm{pH}$ values were made using appropriate concentrations of phosphoric acid (85\%, Aldrich, Gillingham, UK), sodium phosphate monobasic monohydrate (99.6\%, Sigma, Gillingham, UK), di-sodium hydrogen orthophosphate dodecahydrate (99.85\%) and sodium phosphate tribasic dodecahydrate (both: Fisher Scientific, Loughborough, UK). The composition of $100 \mathrm{mM}$ phosphate electrolytes used in this work is provided in Table 1 (calculated using [32]). The prepared phosphate salt solutions were diluted with water to obtain electrolytes of desired concentrations.

All solutions were filtered through $0.2 \mu \mathrm{m}$ filters (Millipore, Hampshire, UK) before use. Sodium tetraborate (99\%), sodium hydroxide pellets (98\%), 1,4-diaminobutane (>99\%) and triethanolamine $(>99.5 \%)$ were purchased from Sigma-Aldrich. The borate buffer of $\sim 45 \mathrm{mM}$ ionic strength at $\mathrm{pH} 9.5$ (i.e. equivalent ionic strength of $15 \mathrm{mM}$, pH 9.5 phosphate buffer, which was estimated using [32]) was prepared by mixing $15 \mathrm{mM}$ sodium tetraborate with $15 \mathrm{mM}$ sodium hydroxide (which was calculated using [33]). For the phenol-sulphuric acid assay, mannose (>99\%), phenol and sulphuric acid (96\%) were also obtained from Sigma-Aldrich.

Vivaspin ${ }^{\mathrm{TM}} 6$ columns (Sartorius, Surrey, UK) with 10,000 Da relative molecular mass $\left(\mathrm{M}_{\mathrm{r}}\right)$ cut-off polyethersulphone membranes were used to replace the $3.2 \mathrm{M}$ ammonium sulphate solution in CBH (Megazyme, Bray, Ireland) from Trichoderma longibrachiatum with water. The concentrations of original and desalted $\mathrm{CBH}$ solutions were $10 \mathrm{mg} / \mathrm{ml}$ and $\sim 8 \mathrm{mg} / \mathrm{ml}$ respectively. A single band of $\mathrm{CBH}$ along with a band of an unknown impurity was observed on analysing the desalted CBH solution using SDS-PAGE under reducing conditions using Criterion ${ }^{\mathrm{TM}} 10-20 \%$ Tris- $\mathrm{HCl}$ precast gels (Bio-Rad Laboratories, Hertfordshire, UK). PageRuler ${ }^{\mathrm{TM}}$ Plus (product number: \#SM1811, Fermentas, York, UK) widerange (10,000-250,000 Da) molecular mass standard was used as a marker and the gels were stained using Coomassie brilliant blue (Bio-Rad Laboratories, Hertfordshire, UK). The desalted enzymes were divided into aliquots of $\sim 40 \mu \mathrm{l}$ and were stored at $-80^{\circ} \mathrm{C}$. Each aliquot was defrosted and diluted by a factor of 8 before CZE analysis.

\subsection{Instrumentation}

The CZE separations reported in this work were performed using a P/ACE ${ }^{\mathrm{TM}} \mathrm{MDQ}$ (Beckman Coulter, High Wycombe, UK) equipped with a deuterium lamp and a photodiode. Polyacrylamide coated fused silica and fused silica capillaries (both: Beckman Coulter) of $50 \mu \mathrm{m}$ internal diameter and total length of $63 \mathrm{~cm}$ with an online detection window at $11 \mathrm{~cm}$ from the outlet end were used for the CZE analysis of the glycoforms of CBH. The desired capillary was installed in a cartridge which allowed liquid cooling to maintain a constant capillary temperature of $25^{\circ} \mathrm{C}$. Software, 32 Karat $^{\mathrm{TM}}$ version 4.0 (Beckman Coulter, High Wycombe, UK), was used to control the instrument and to collect data at 4 samples/s.

A new fused silica capillary was flushed with $\mathrm{H}_{2} \mathrm{O}, 1 \mathrm{M} \mathrm{NaOH}$, $\mathrm{H}_{2} \mathrm{O}$ and electrolyte by applying a pressure of $1.38 \times 10^{5} \mathrm{~Pa}$ for $2 \mathrm{~min}, 1 \mathrm{~min}, 5 \mathrm{~min}$ and $15 \mathrm{~min}$ respectively before use. While the above procedure was also followed to prepare the capillary between different $\mathrm{pH}$ electrolytes, it was simply washed with electrolyte for $2 \mathrm{~min}$ between runs. Instead of using $\mathrm{NaOH}, 0.1 \mathrm{M} \mathrm{HCl}$ was used for preparing polyacrylamide coated fused silica capillaries. A sample plug was introduced by applying a pressure of $3.45 \times 10^{3}$ Pa for $5 \mathrm{~s}$. The glycoforms were detected at $214 \mathrm{~nm}$ unless otherwise stated.

\subsection{Removal of carbohydrate moieties of $\mathrm{CBH}$}

The protein deglycosylation mix (product number: P6039) containing enzymes for removing $\mathrm{N}$ - and O-linked glycans were obtained from New England BioLabs (Hertfordshire, UK). CBH was deglycosylated under non-denaturing conditions according to the protocol provided by the manufacturer. The standard protocol provided by the manufacturer suggested adding $5 \mu$ l of deglycosylation mix and $5 \mu \mathrm{l}$ of reaction buffer to $100 \mu \mathrm{g}$ of glycoprotein in $40 \mu \mathrm{l}$ of water. It was recommended to incubate the solution at $37^{\circ} \mathrm{C}$ for $4 \mathrm{~h}$. However, the concentration of $\mathrm{CBH}$ and the time of its incubation with the deglycosylation mix were optimised. The optimal $\mathrm{CBH}$ concentration and time of incubation were found to be $1 \mathrm{mg} / \mathrm{ml}$ and $48 \mathrm{~h}$ respectively. 
Table 1

Composition of $100 \mathrm{mM}$ phosphate electrolytes (all amounts are in $\mathrm{mM}$ ).

\begin{tabular}{|c|c|c|c|c|c|c|c|c|c|c|c|c|}
\hline $\mathrm{pH}$ & 3.5 & 4.5 & 5.0 & 5.5 & 6.0 & 6.5 & 7.5 & 9.0 & 9.5 & 10.5 & 11.5 & 12.5 \\
\hline $\mathrm{H}_{3} \mathrm{PO}_{4}$ & 4.5 & 0.1 & & & & & & & & & & \\
\hline $\mathrm{NaH}_{2} \mathrm{PO}_{4} \cdot \mathrm{H}_{2} \mathrm{O}$ & 95.5 & 99.9 & 98.8 & 95.8 & 87.9 & 69.8 & 18.8 & 0.7 & 0.2 & & & \\
\hline $\mathrm{Na}_{2} \mathrm{HPO}_{4} \cdot 12 \mathrm{H}_{2} \mathrm{O}$ & & & 1.2 & 4.2 & 12.1 & 30.2 & 81.2 & 99.3 & 99.8 & 98.2 & 83.7 & 8.1 \\
\hline $\mathrm{Na}_{3} \mathrm{PO}_{4} \cdot 12 \mathrm{H}_{2} \mathrm{O}$ & & & & & & & & & & 1.8 & 16.3 & 91.9 \\
\hline
\end{tabular}

\section{Results and discussion}

\subsection{Optimisation of CZE separation of glycoforms of CBH using a fused silica capillary}

As glycans present in $\mathrm{CBH}$ are known to contain large number of mannose residues, the initial CZE runs for studying the glycoforms of $\mathrm{CBH}$ were performed using $15 \mathrm{mM}$ phosphate electrolytes of $\mathrm{pH}$ between 8 and 10. At pH 9.5, shoulders were observed on the primary peak of $\mathrm{CBH}$ (Fig. 1, results of $\mathrm{pH} 8.5$ and 10.5 are not shown).

In an attempt to resolve these peaks, 1,4-diaminobutane $(0.2 \mathrm{mM}$ and $1 \mathrm{mM})$ or triethanolamine $(1 \mathrm{mM})$ was added to the background electrolyte of $\mathrm{pH} 9.5$ to suppress electroosmotic flow and/or to reduce interactions of $\mathrm{CBH}$ with the walls of fused silica capillary. However, when either of these additives was present in the electrolyte, not even a single peak was detected within $2 \mathrm{~h}$. As borate has been reported to increase the resolution of the microheterogeneous components by forming complexes with the hydroxyl groups of glycan moieties [12], the borate electrolyte of $\mathrm{pH} 9.5$ and of ionic strength equal to the ionic strength of $15 \mathrm{mM}$ phosphate electrolyte at this $\mathrm{pH}$ values (i.e. $\sim 45 \mathrm{mM}$ ) was tried. However, the separation was not improved. This is consistent with some previously reported CZE studies [24]. This necessitated undertaking a systematic study to develop a CZE method suitable for investigating the microheterogeneities present in $\mathrm{CBH}$.

As $\mathrm{pH}$ controls the dissociation degree of analytes and magnitude of electroosmotic flow, the effect of $\mathrm{pH}$ was studied using $15 \mathrm{mM}$ phosphate electrolytes over a $\mathrm{pH}$ range of 12.5-3.5 (Fig. 1). It should be noted that the isoelectric point of $\mathrm{CBH}$ from $T$. ree-

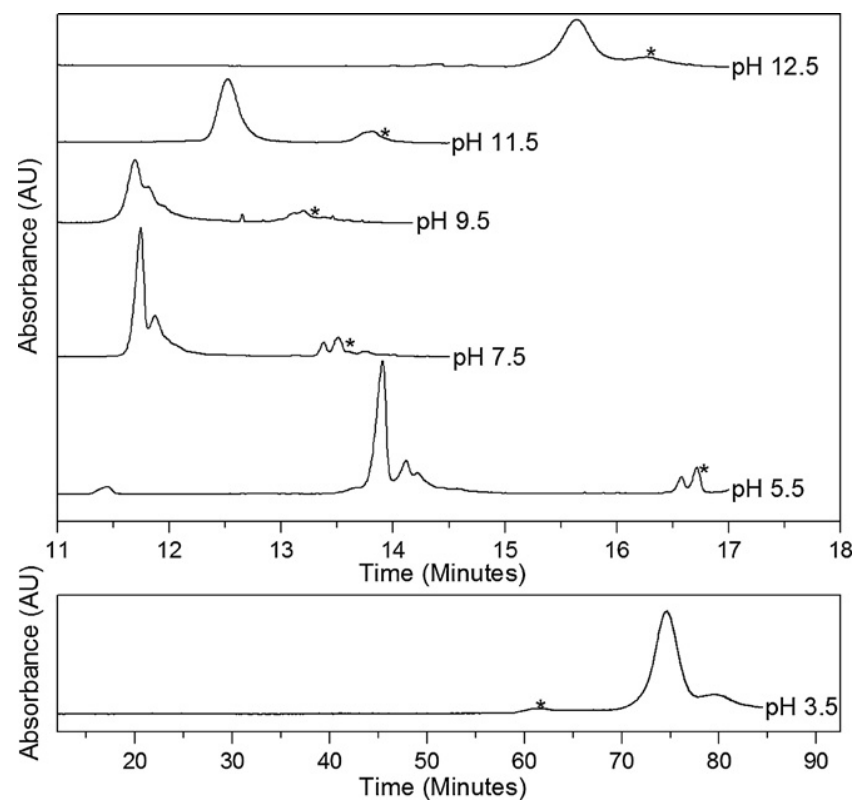

Fig. 1. Effect of $\mathrm{pH}$ on CZE separation of glycoforms of $\mathrm{CBH}$ (15 mM phosphate electrolyte, normal polarity: $10 \mathrm{kV}$, fused silica capillary, and ${ }^{*}$ : unknown impurity in $\mathrm{CBH})$. sei is 3.9 [34]. Therefore, $\mathrm{CBH}$ is negatively charged at all tried $\mathrm{pH}$ values except at $\mathrm{pH}$ 3.5. This study suggested that $15 \mathrm{mM}$ phosphate electrolytes of $\mathrm{pH}$ in a region close to 5.5 are best suited for the separation of glycoconjugates of $\mathrm{CBH}$. Hence, the $\mathrm{pH}$ of $15 \mathrm{mM}$ phosphate electrolytes was varied in steps of 0.5 in the $\mathrm{pH}$ range of 4.5-6.0. From Fig. 2 it is clear that a $\mathrm{pH}$ of 4.5 provided the optimal charge-to-mass ratio for resolving the glycoforms of $\mathrm{CBH}$.

The glycoforms of CBH differ primarily in the number of mannose groups present in oligosaccharides attached to them [35]. As $\mathrm{pH} 4.5$ is close to the isoelectric point of $\mathrm{CBH}$ (i.e. 3.9), the enzyme is slightly charged. Hence, any change in charge or size due to variations in the number of mannose groups was pronounced at $\mathrm{pH} 4.5$ [36].

Previously reported studies employed high concentration buffers for the CZE separation of the glycoforms of proteins. Therefore, the effect of concentration of phosphate electrolyte on the CZE separation of glycoconjugates of $\mathrm{CBH}$ was studied next. The variation in the concentration of phosphate electrolytes between $15 \mathrm{mM}$ and $60 \mathrm{mM}$ did not have any noticeable effect on the separation (results not shown). In short, the use of $15 \mathrm{mM}, \mathrm{pH} 4.5$ phosphate electrolyte was found to be optimal for the separation of glycoforms of $\mathrm{CBH}$ in fused silica capillaries. Under these conditions, the separation of glycoforms of $\mathrm{CBH}$ was accomplished within $20 \mathrm{~min}$.

After repeating the experiment three times, the migration time and the standard deviation were found to be $16.9 \mathrm{~min}$ and $2.4 \mathrm{~min}$ respectively. The reason behind the high standard deviation of the migration time could be the low buffering capacity of phosphate at $\mathrm{pH} 4.5$ [37]. Although carboxylic acid buffers such as ammonium acetate have good buffering capacity at $\mathrm{pH} 4.5$, one of their disadvantages is their relatively high UV cut-off value (e.g. $220 \mathrm{~nm}$ at $100 \mathrm{mM}$ ) [38]. Therefore, the separation of the glycoforms of $\mathrm{CBH}$ at the $\mathrm{pH}$ within the buffering capacity (i.e. either between 1.1 and 3.1 or between 6.2 and 8.2 ) of the low UV-absorbent phosphate is desirable to ensure reproducibility of migration time and high sensitivity of detection. Therefore, to investigate a possibility that the use of high buffering capacity phosphate buffer may be optimum for the separation of glycoconjugates of $\mathrm{CBH}$, a coated (in particular, polyacrylamide) fused silica capillary was tried.

\subsection{Optimisation of CZE separation of glycoforms of CBH using a polyacrylamide coated fused silica capillary}

As the coating is only stable in the $\mathrm{pH}$ range between 5 and 9 , the electrophoretic behaviour of $\mathrm{CBH}$ in this range was studied using $50 \mathrm{mM}$ phosphate electrolyte (Fig. 3). The separation was performed by applying a voltage of $-30 \mathrm{kV}$ in order to accomplish separation in $\sim 30 \mathrm{~min}$. For the case of using a polyacrylamide coated fused silica capillary, the optimum $\mathrm{pH}$ for the separation of glycoforms was found to be 7.5 (which is within the buffering capacity of phosphate). The migration time and the effective mobility of the glycoconjugates of $\mathrm{CBH}$ are summarised in Table 2.

The concentration of phosphate buffer at $\mathrm{pH} 7.5$ was then varied between 10 and 75 mM (Fig. 4). Yim et al. [36] have suggested 

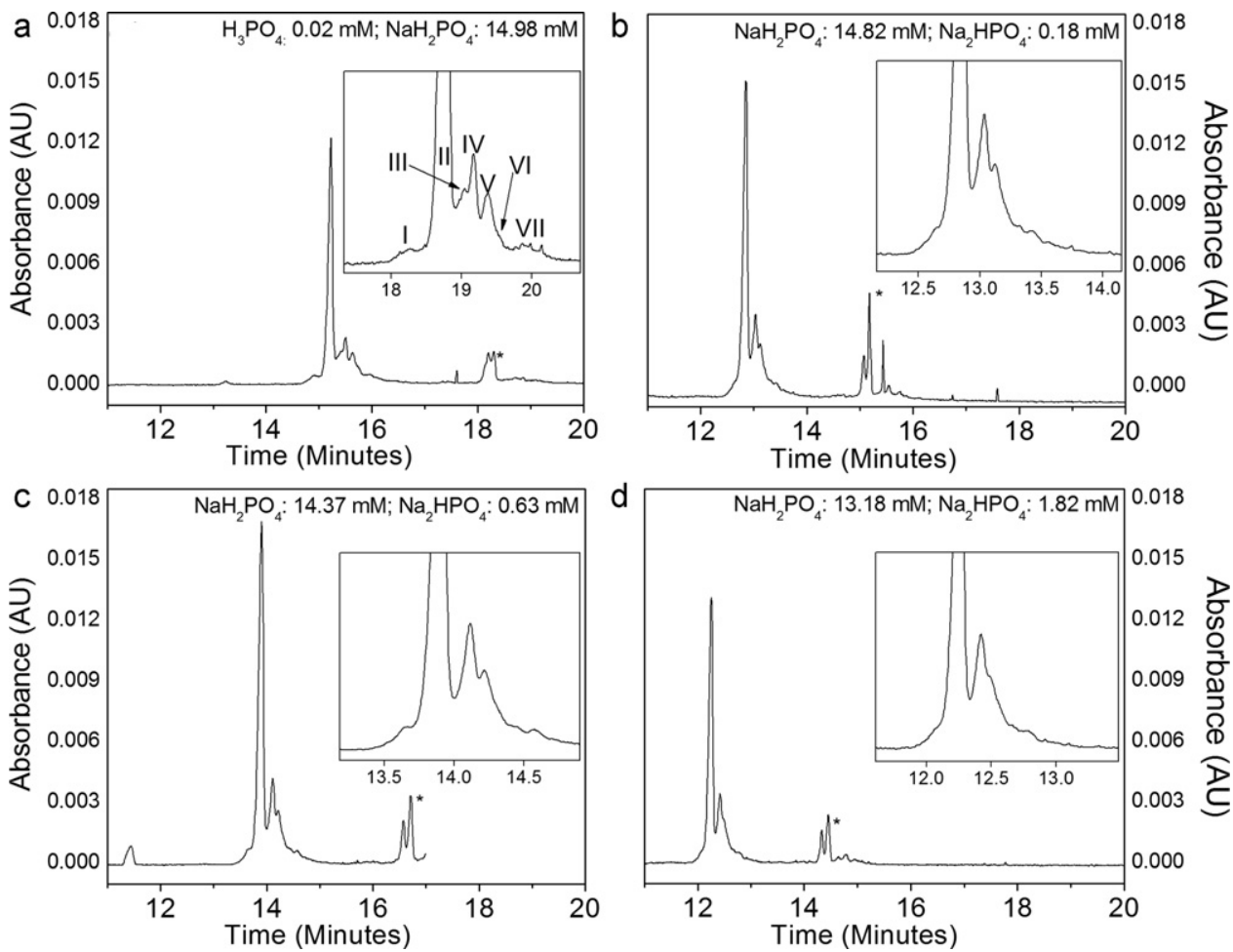

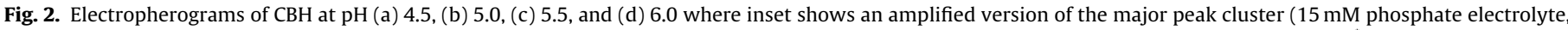

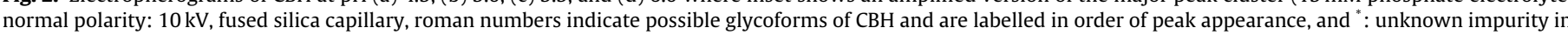
$\mathrm{CBH})$.

that attachment of mannose residues to a charged particle (in this case, $\mathrm{CBH}$ ) extends the distance of the shear plane from its surface. Furthermore, according to the diffuse double layer model and the Poisson-Boltzmann equation, the potential drops as an exponen- tial function of distance from the surface of the particle. Therefore, a change in the number of mannose groups will affect the zeta potential and hence the mobility of the particle. In addition, the rate of decay of potential from the surface of a charged particle
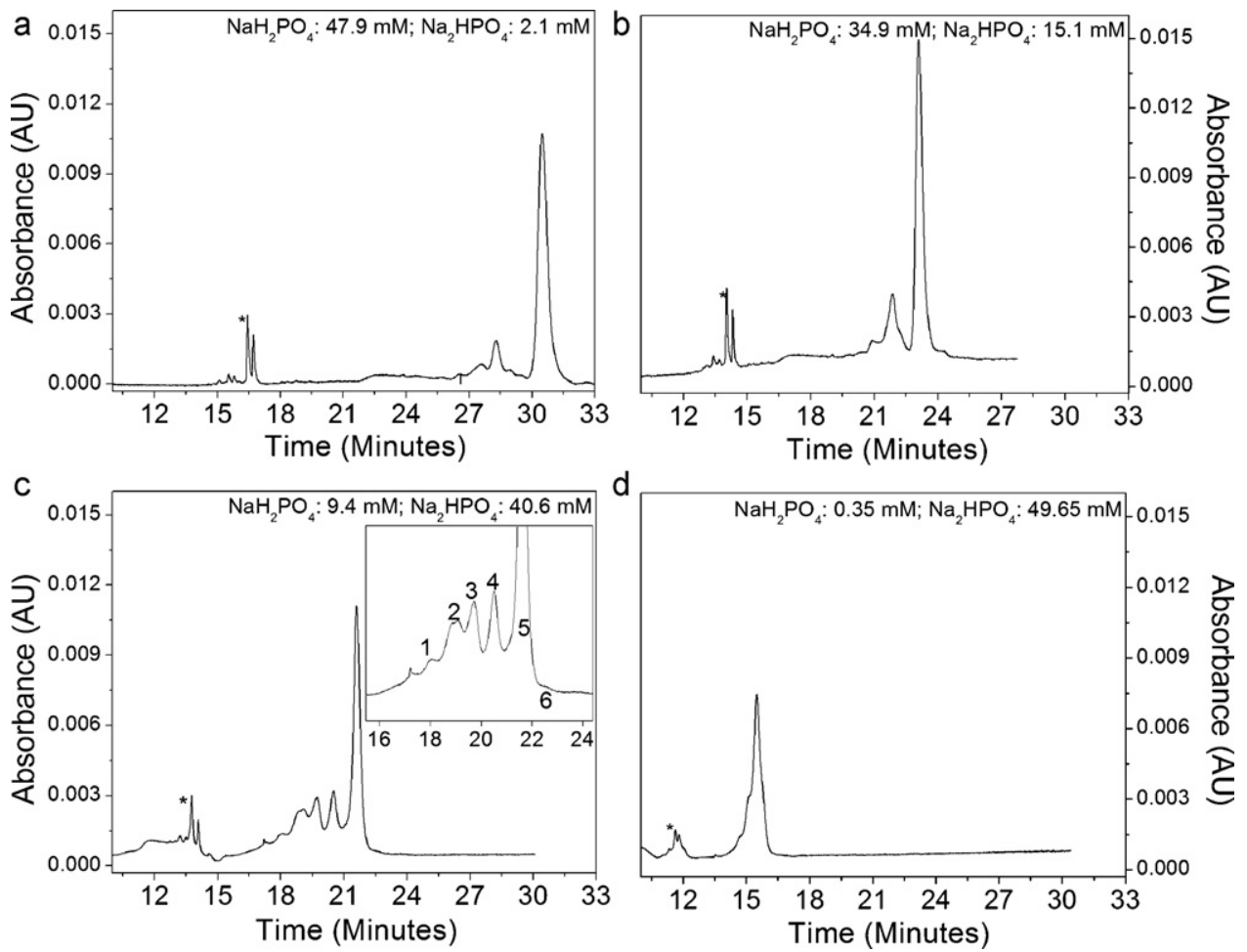

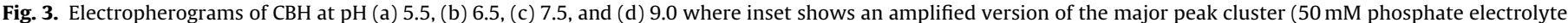

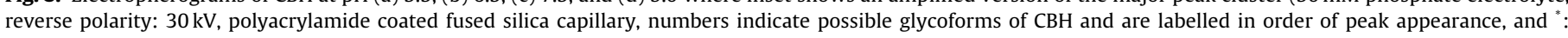
unknown impurity in $\mathrm{CBH}$ ). 

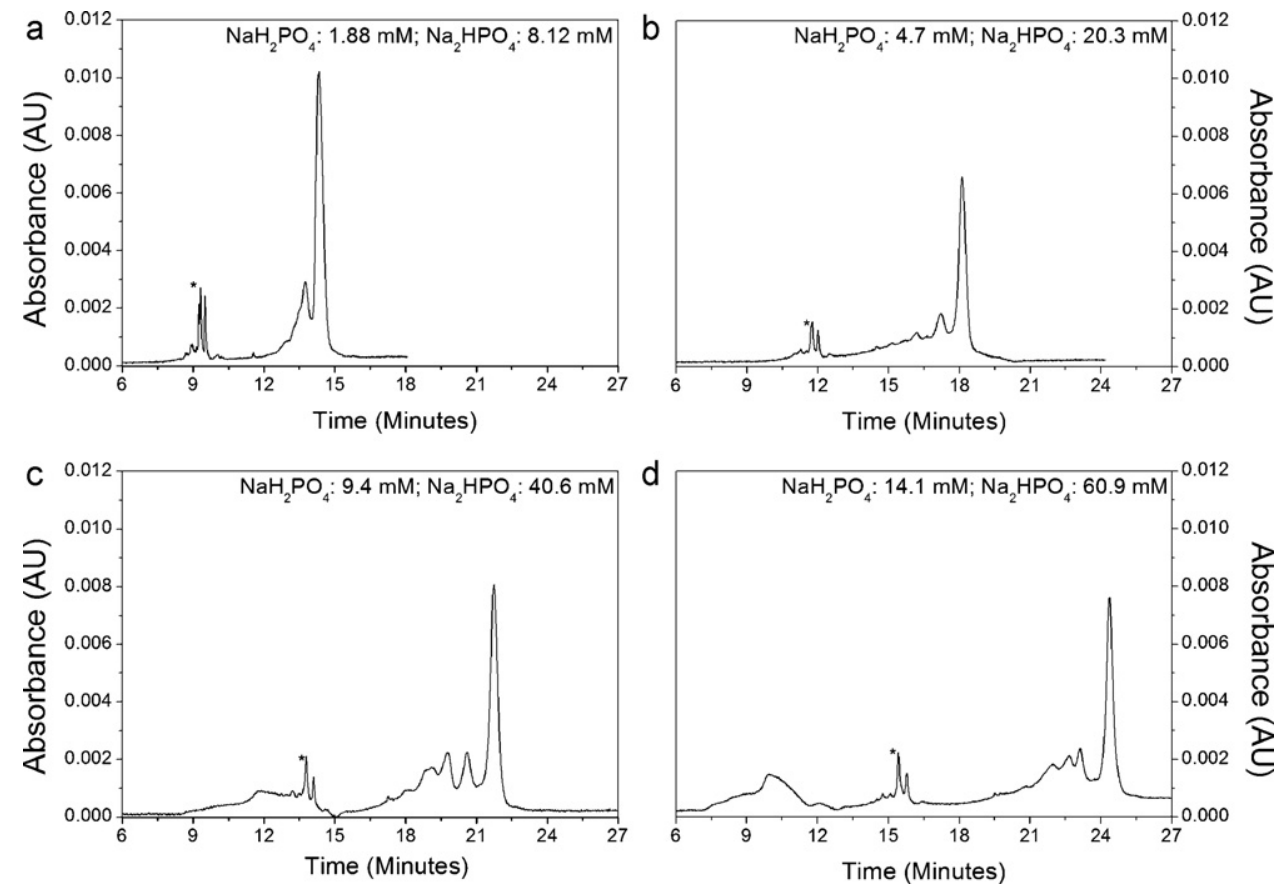

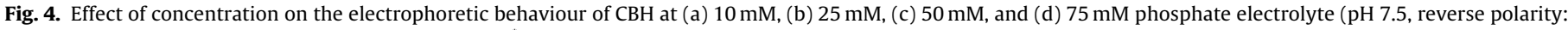
$30 \mathrm{kV}$, polyacrylamide coated fused silica capillary, and ${ }^{*}$ : unknown impurity in $\mathrm{CBH}$ ).

is a direct function of the ionic strength (and hence the concentration) of the separation electrolyte [39]. In other words, as the concentration of the electrolyte increases, the difference in mobility due to shifting of the shear plane as a result of variations in the number of mannose groups bound to $\mathrm{CBH}$ will rise. As a consequence, the resolution of the CZE separation of glycoforms of
$\mathrm{CBH}$ was improved as the concentration increases from $10 \mathrm{mM}$ to $50 \mathrm{mM}$. The resolution however, decreased at $75 \mathrm{mM}$ due to Joule heating.

The experiment using $50 \mathrm{mM}$ phosphate buffer was repeated three times and the migration time of the major peak was found to be $21.6 \pm 0.1 \mathrm{~min}$. Finally, the separation of the glycoforms of
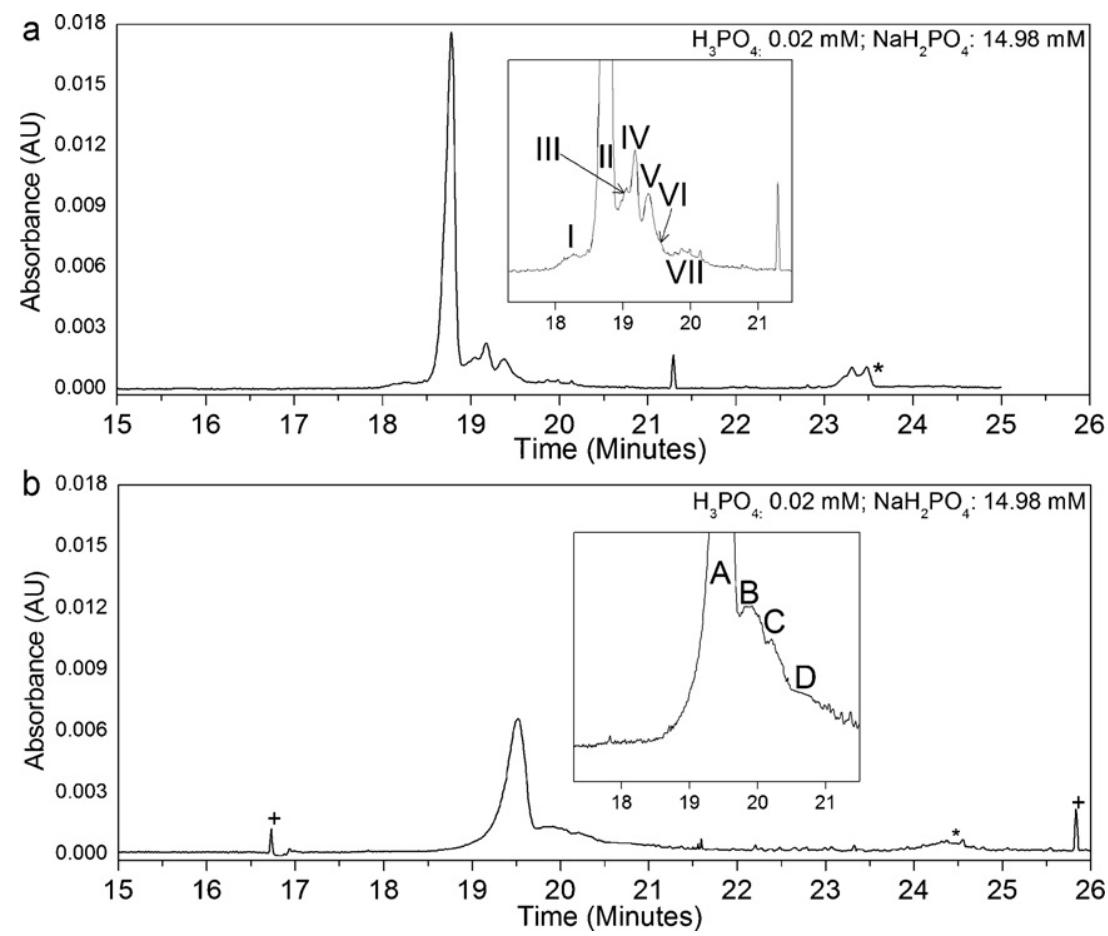

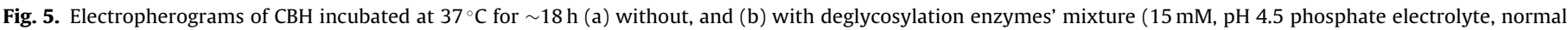

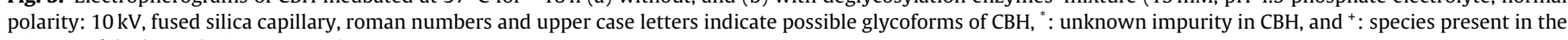
mixture of deglycosylation enzymes). 
Table 2

Migration time and effective mobility of the glycoconjugates of $\mathrm{CBH}(50 \mathrm{mM} \mathrm{pH}$ 7.5 phosphate buffer, reverse polarity: $-30 \mathrm{kV}$, polyacrylamide coated fused silica capillary, total length of $63 \mathrm{~cm}$ with an on-line detection window at $11 \mathrm{~cm}$ from the outlet end, and peak numbers are same as in Fig. 3).

\begin{tabular}{lll}
\hline Peak no. & $\begin{array}{l}\text { Migration time } \\
(\mathrm{min})\end{array}$ & $\begin{array}{l}\text { Effective mobility } \\
\left(\times 10^{-5} \mathrm{~cm}^{2} \mathrm{~V}^{-1} \mathrm{~s}^{-1}\right)\end{array}$ \\
\hline 1 & 18.0 & 10.11 \\
2 & 18.9 & 9.63 \\
3 & 19.7 & 9.24 \\
4 & 20.5 & 8.88 \\
5 & 21.6 & 8.42 \\
6 & 22.6 & 8.05 \\
\hline
\end{tabular}

$\mathrm{CBH}$ with the use of a polyacrylamide coated fused silica capillary, $50 \mathrm{mM}$, pH 7.5 phosphate buffer was accomplished within 25 min.

\subsection{Deglycosylation of $\mathrm{CBH}$}

It was thought prudent to compare the electropherograms of glycosylated and non-glycosylated $\mathrm{CBH}$ to verify that the identified secondary peaks are indeed the glycoforms of $\mathrm{CBH}$. Hence, the conditions required to remove oligosaccharides attached to $\mathrm{CBH}$ were optimised first. In particular, $10 \mu \mathrm{l}$ of deglycosylation enzymes' mixture and $10 \mu \mathrm{l}$ of reaction buffer were added to $80 \mu \mathrm{l}$ solutions of $0.5 \mathrm{mg} / \mathrm{ml}, 1 \mathrm{mg} / \mathrm{ml}$ and $2 \mathrm{mg} / \mathrm{ml}$ of $\mathrm{CBH}$ in the respective vials. The vials were incubated at $37^{\circ} \mathrm{C}$ and $20 \mu \mathrm{l}$ of the solution was collected from each vial at regular intervals for $\sim 48 \mathrm{~h}$. The amount of released sugars in each sample was monitored using the phenol-sulphuric acid method [40]. Briefly, $0.5 \mathrm{ml}$ of $4 \%(\mathrm{~m} / \mathrm{v})$ phenol and $2.5 \mathrm{ml}$ of sulphuric acid were added to each collected sample. Following this, the absorbance of each solution was measured at $490 \mathrm{~nm}$. The amount of released sugars was estimated according to the standard curve obtained by preparing a dilution series of mannose. The equation for the curve is Absorbance $=16.9$ ([mannose $]-0.4211$ ) with $r^{2}$ of 0.998 and limit of detection (defined using [41]) of $1.86 \mu$.

The percentage of the mass of glycans with respect to the total mass of $\mathrm{CBH}$ is known to be $\sim 14 \%(\mathrm{~m} / \mathrm{m})$ [42]. After $\sim 48 \mathrm{~h}$, the percentage of the mass of glycans with respect to the total mass of $\mathrm{CBH}$ was $\sim 13.5 \%(\mathrm{~m} / \mathrm{m})$ (results not shown). Therefore, it is believed that most carbohydrate moieties attached to $\mathrm{CBH}$ were removed in $\sim 48 \mathrm{~h}$. In addition, the amount of sugar released by $2 \mathrm{mg} / \mathrm{ml}$ of $\mathrm{CBH}$ after $48 \mathrm{~h}$ was less than twice the amount released by $1 \mathrm{mg} / \mathrm{ml} \mathrm{CBH}$. Therefore, it appears that the attached oligosaccharides were not efficiently released if the concentration of $\mathrm{CBH}$ to the concentration of enzymes' mixture is too high (in this case, $2 \mathrm{mg} / \mathrm{ml}$ ).

Hence, $\sim 1 \mathrm{mg} / \mathrm{ml}$ of $\mathrm{CBH}$ solution was mixed with the mixture of enzymes capable of removing the attached glycans and incubated at $37^{\circ} \mathrm{C}$. After $\sim 18 \mathrm{~h}$, the solution was analysed using the developed CZE method (Fig. 5). A comparison of Fig. 5(a) and (b) demonstrated that changes in the peak pattern of $\mathrm{CBH}$ are due to removal of sugars instead of its denaturation which may be possible as a result of its storage at $37^{\circ} \mathrm{C}$. Furthermore, a reduction in the number of peaks in Fig. 5(b) shows that the peaks marked in Fig. 2(a) are indeed the glycoforms of $\mathrm{CBH}$. It should also be noted that as the number of sugar groups bound to $\mathrm{CBH}$ reduces, its solubility decreases. As a result, the height of the primary peak in Fig. 5(b) was lower than in Fig. 5(a).

\section{Conclusions}

CZE is a high resolution analysis technique which shows great promise for the separation of glycoconjugates of proteins, espe- cially in its simplicity, capability of automation and reduced analysis times. There is not a standard approach for analysing glycoforms by CZE, due to their inherent variability, and the selection of a suitable electrolyte system must be made on a case by case basis.

This study for the first time successfully developed a CZE method for the analysis of the glycoforms of $\mathrm{CBH}$. The developed method analysed the glycoconjugates of $\mathrm{CBH}$ in an intact form without requiring additives and labelling the glycoprotein. The method is suitable for rapid testing of microheterogeneities present in $\mathrm{CBH}$ due to glycosylation. The method will be beneficial in characterising glycoforms of $\mathrm{CBH}$ expressed in heterologous hosts, such as plants. It could be used by existing manufacturers supplying $\mathrm{CBH}$ for batch-to-batch testing of the protein. The method could also be used by the bioethanol process industry for quality control purposes by ensuring that glycosylation-related microheterogeneities present in $\mathrm{CBH}$ expressed in plants (and hence its cellulose degrading activity) are consistent in every batch.

\section{Acknowledgements}

This research was funded by Syngenta and the University of Manchester.

\section{References}

[1] N. Deshpande, M.R. Wilkins, N. Packer, H. Nevalainen, Glycobiology 18 (2008) 626.

[2] H. Geyer, R. Geyer, Biochim. Biophys. Acta 1764 (2006) 1853.

[3] H.J. Gabius, S. Gabius, Glycosciences: Status and Perspectives, Chapman \& Hall, Weinheim, 1997.

[4] S. Honda, S. Suzuki, Anal. Biochem. 142 (1984) 167.

[5] R.R. Townsend, M.R. Hardy, Y.C. Lee, Methods Enzymol. 179 (1989) 65.

[6] D.C. Andersen, C.F. Goochee, G. Cooper, M. Weitzhandler, Glycobiology 4 (1994) 459.

[7] T. Patel, J. Bruce, A. Merry, C. Bigge, M. Wormald, A. Jacques, R. Parekh, Biochemistry 32 (1993) 679

[8] F. Lamari, M. Militsopoulou, X. Gioldassi, N.K. Karamanos, Fresenius J. Anal. Chem. 371 (2001) 157.

[9] S. Suzuki, S. Honda, Electrophoresis 19 (1998) 2539.

[10] F. Lamari, R. Kuhn, N.K. Karamanos, J. Chromatogr. B 793 (2003) 15.

[11] B. Lu, D. Westerlund, Electrophoresis 17 (1996) 325.

[12] S. Hoffstetter-Kuhn, A.P. Ernst, E. Gassmann, H.M. Widmer, Anal. Chem. 63 (1991) 1541.

[13] J.P.M. Hui, P. Lanthier, T.C. White, S.G. McHugh, M. Yaguchi, R. Roy, P. Thibault J. Chromatogr. B: Biomed. Sci. Appl. 752 (2001) 349.

[14] T. de Beer, C.W.E.M. van Zuylen, K. Hård, R. Boelens, R. Kaptein, J.P. Kamerling J.F.G. Vliegenthart, FEBS Lett. 348 (1994) 1.

[15] Y. Yamaguchi, T. Takizawa, K. Kato, Y. Arata, I. Shimada, J. Biomol. NMR 18 (2000) 357.

[16] B. Nilsson, Mol. Biotechnol. 2 (1994) 243.

[17] D.J. Harvey, P.M. Rudd, R.H. Bateman, R.S. Bordoli, K. Howes, J.B. Hoyes, R.G. Vickers, Org. Mass Spectrom. 29 (1994) 753.

[18] J.P.M. Hui, T.C. White, P. Thibault, Glycobiology 12 (2002) 837

[19] S. Amon, A.D. Zamfir, A. Rizzi, Electrophoresis 29 (2008) 2485.

[20] E. Balaguer, C. Neusüß, Chromatographia 64 (2006) 351.

[21] U.M. Demelbauer, A. Plematl, L. Kremser, G. Allmaier, D. Josic, A. Rizzi, Electrophoresis 25 (2004) 2026.

[22] J. Barbosa, V. Sanz-Nebot, F. Benavente, E. Giménez, FABAD J. Pharm. Sci. 31 (2006) 63.

[23] M. Pattky, C. Huhn, Bioanal. Rev. 2 (2010) 115.

[24] Y. Chen, J. Chromatogr. A 768 (1997) 39.

[25] Z. El Rassi, Electrophoresis 31 (2010) 174

[26] M. Taverna, N.T. Tran, D. Ferrier, in: P. Thibault, S. Honda (Eds.), Capillary Electrophoresis of Carbohydrates (Methods in Molecular Biology), 1st ed., Humana Press, New Jersey, 2010, p. 187.

[27] S. Hoffstetter Kuhn, G. Alt, R. Kuhn, Electrophoresis 17 (1996) 418.

[28] J.P. Landers, R.P. Oda, B.J. Madden, T.C. Spelsberg, Anal. Biochem. 205 (1992) 115.

[29] B. Yeung, T.J. Porter, J.E. Vath, Anal. Chem. 69 (1997) 2510.

[30] B. Henrissat, H. Driguez, C. Viet, M. Schülein, Nat. Biotechnol. 3 (1985) 722.

[31] T.Jeoh, W. Michener, M.E. Himmel, S.R. Decker, W.S. Adney, Biotechnol. Biofuels 1 (2008) 10.

[32] Buffer Calculator, http://dbr.csoft.net/chem/bufcalc.php (accessed 28.04.11).

[33] Peak Master 5.1, http://web.natur.cuni.cz/ gas/ (accessed 28.04.11).

[34] G. Henriksson, A. Englund, G. Johansson, P. Lundahl, Electrophoresis 16 (1995) 1377. 
[35] M. Maras, A. De-Bruyn, J. Schraml, P. Herdewijn, M. Claeyssens, W. Fiers, R. Contreras, Eur. J. Biochem. 245 (1997) 617.

[36] K. Yim, J. Abrams, A. Hsu, J. Chromatogr. A 716 (1995) 401.

[37] E.T. Urbansky, M.R. Schock, J. Chem. Educ. 77 (2000) 1640.

[38] C.K. Lim, T.J. Peters, J. Chromatogr. 316 (1984) 397.

[39] W. Friedl, J.C. Reijenga, E. Kenndler, J. Chromatogr. A 709 (1995) 163.
[40] S.S. Nayak, T.N. Pattabiraman, Clin. Chim. Acta 109 (1981) 267.

[41] J.N. Miller, J.C. Miller, Statistics and Chemometrics for Analytical Chemistry, 5 th ed., Pearson Prentice Hall, Harlow, Essex, 2005.

[42] S. Godbole, S.R. Decker, R.A. Nieves, W.S. Adney, T.B. Vinzant, J.O. Baker, S.R. Thomas, M.E. Himmel, Biotechnol. Prog. 15 (1999) 828. 